\title{
Transformation of the tumour microenvironment by a CD40 agonist antibody correlates with improved responses to PD-L1 blockade in a mouse orthotopic pancreatic tumour model
}

\author{
Nadia M. Luheshi, ${ }^{1, *}$, Jane Coates-Ulrichsen ${ }^{1, *}$, James Harper $^{1,{ }^{*}}$, Stefanie Mullins ${ }^{1}$, \\ Michal G. Sulikowski ${ }^{1}$, Philip Martin ${ }^{2}$, Lee Brown ${ }^{1}$, Arthur Lewis ${ }^{1}$, Gareth Davies ${ }^{1}$, \\ Michelle Morrow ${ }^{1}$, Robert W. Wilkinson ${ }^{1}$ \\ ${ }^{1}$ MedImmune Ltd., Cambridge CB21 6GH, UK \\ ${ }^{2}$ MedImmune LLC., Gaithersburg, MD 20878, USA \\ *These authors have contributed equally to this work \\ Correspondence to: Nadia M. Luheshi, e-mail: Iuheshin@medimmune.com \\ Keywords: CD40, PD-L1, pancreatic cancer, microenvironment \\ Received: December 18, $2015 \quad$ Accepted: February 14, $2016 \quad$ Published: February 23, 2016
}

\section{ABSTRACT}

Despite the availability of recently developed chemotherapy regimens, survival times for pancreatic cancer patients remain poor. These patients also respond poorly to immune checkpoint blockade therapies (anti-CTLA-4, anti-PD-L1, anti-PD-1), which suggests the presence of additional immunosuppressive mechanisms in the pancreatic tumour microenvironment (TME). CD40 agonist antibodies ( $\alpha$ CD40) promote antigen presenting cell (APC) maturation and enhance macrophage tumouricidal activity, and may therefore alter the pancreatic TME to increase sensitivity to immune checkpoint blockade. Here, we test whether $\alpha$ CD40 transforms the TME in a mouse syngeneic orthotopic model of pancreatic cancer, to increase sensitivity to PD-L1 blockade. We found that whilst mice bearing orthotopic Pan02 tumours responded poorly to PD-L1 blockade, $\alpha$ CD40 improved overall survival. $\alpha C D 40$ transformed the TME, upregulating Th1 chemokines, increasing cytotoxic $T$ cell infiltration and promoting formation of an immune cell-rich capsule separating the tumour from the normal pancreas. Furthermore, $\alpha C D 40$ drove systemic APC maturation, memory $T$ cell expansion, and upregulated tumour and systemic PD-L1 expression. Combining $\alpha$ CD40 with PD-L1 blockade enhanced anti-tumour immunity and improved overall survival versus either monotherapy. These data provide further support for the potential of combining $\alpha$ CD40 with immune checkpoint blockade to promote anti-tumour immunity in pancreatic cancer.

\section{INTRODUCTION}

Tumours employ a number of mechanisms to escape detection and elimination by the adaptive immune system [1]. Tumour cells may directly escape T cell surveillance by downregulating expression and presentation of potentially immunogenic tumour-associated antigens $[2,3]$. In addition, immunosuppressive mediators produced by tumour cells, stroma and tumour infiltrating leukocytes can drive effector $\mathrm{T}$ cell inactivation and exclusion of effector $\mathrm{T}$ cells from the microenvironment [4].

The PD-1 (programmed cell death protein 1) and CTLA-4 (cytotoxic lymphocyte-associated antigen 4) immune checkpoint pathways can both contribute to tumour immune evasion. PD-L1 (programmed death ligand 1) expressed on tumour cells and infiltrating myeloid cells engages PD-1 on activated $\mathrm{T}$ cells, downregulating $\mathrm{T}$ cell effector functions [5]. CTLA-4 on activated $\mathrm{T}$ cells binds to co-stimulatory molecules on antigen presenting cells, inhibiting further T cell activation and expansion, and facilitating suppression by regulatory $\mathrm{T}$ cells $\left(\mathrm{T}_{\mathrm{reg}}\right)$ [6]. Antibody therapies blocking PD-1, PDL1 and CTLA-4 function enhance anti-tumour immunity, leading to durable clinical responses for a subset of patients with melanoma, lung cancer and other tumour types [7]. However, patients with pancreatic cancer, an aggressive disease with only a 7.2\% 5 year survival rate, 
are reported to respond poorly to checkpoint blockade therapies [8, 9].

Melanoma patients that respond to PD-1 blockade are reported to show baseline PD-L1 expression and CD8 ${ }^{+}$ effector $\mathrm{T}$ cell infiltration in their tumours [10-12]. This has led to the suggestion that PD-L1 / PD-1 blockade may be most effective where an existing anti-tumour $\mathrm{CD}^{+}$effector $\mathrm{T}$ cell immune response is actively being restrained by PD-L1 expression [7]. The pancreatic tumour microenvironment (TME) is dominated by a dense desmoplastic stroma infiltrated with immunosuppressive myeloid-derived suppressor cells, macrophages, fibroblasts and $\mathrm{T}_{\text {reg }}$ [13]. In contrast to melanoma tumours, effector $\mathrm{T}$ cells are often excluded from pancreatic tumours, and those that reach the TME appear inactive $[14,15]$. The lack of response of pancreatic cancer patients to checkpoint blockade therapies has thus been proposed to be due to the establishment of the pancreatic TME as an "immune privileged" site [16].

Various strategies have therefore been developed to transform the immunosuppressive pancreatic TME, and so enhance the response of pancreatic cancer patients to immune checkpoint blockade therapies. A cell-based cancer vaccine, GVAX, was able to induce the formation of tertiary lymphoid aggregates in pancreatic cancer patient tumours, and resulted in objective clinical responses in combination with anti-CTLA-4 $[17,18]$. In pre-clinical mouse models of pancreatic cancer (e.g. KPC model, $\mathrm{KRAS}^{\mathrm{LSL}-\mathrm{G} 12 \mathrm{D} /+} / \mathrm{Trp} 53^{\mathrm{LSL}-\mathrm{R} 172 \mathrm{H} /+} / \mathrm{Pdx}$-1-Cre) macrophage depletion with CSF1R inhibitors, or blockade of fibroblastderived CXCL12 activity with a CXCR4 inhibitor, enhanced $\mathrm{T}$ cell infiltration and anti-tumour activity of $\alpha$ PD-L1/ $\alpha$ PD- 1 and $\alpha$ CTLA4 $[19,20]$.

CD40 agonistic antibodies $(\alpha C D 40)$ in combination with gemcitabine have been reported to show early signs of clinical activity in pancreatic cancer patients [21]. CD40 agonism promotes macrophage and dendritic cell maturation, licenses cross-presentation of antigens to cytotoxic T cells, and promotes direct macrophage tumouricidal activity [22-24]. In both spontaneous genetic and transplantable KPC pancreatic tumour models, $\alpha \mathrm{CD} 40$ given alone or in combination with chemotherapy inhibited tumour growth $[25,26]$. Furthermore, the combination of $\alpha$ CD40 plus chemotherapy increased sensitivity to PD-1 / CTLA4 blockade, driving $\mathrm{T}$ cell-dependent anti-tumour immunity in a subcutaneous transplantable KPC model, and improving overall survival in the spontaneous KPC model [27].

Here we build on the above results by investigating the mechanism by which $\alpha \mathrm{CD} 40$ improves sensitivity to PD-L1 blockade in pancreatic tumours. Since s.c. Pan02 tumour-bearing mice respond well to immune checkpoint blockade [28, 29], we developed a syngeneic orthotopic Pan02 model that better reflected the situation for patients and responded poorly to PD-L1 or CTLA-4 blockade. In contrast, we found that $\alpha \mathrm{CD} 40$ delayed tumour growth and extended overall survival of orthotopic Pan02 tumour bearing mice. $\alpha \mathrm{CD} 40$ treatment induced marked changes in the tumour immune microenvironment, promoting the formation of an immune cell rich capsule separating the tumour from the normal pancreas, enhancing Th1 chemokine expression and cytotoxic $\mathrm{T}$ cell infiltration, and increasing PD-L1 expression. The combination of $\alpha \mathrm{CD} 40$ and $\alpha$ PD-L1 enhanced anti-tumour immunity and significantly improved overall survival. These data add further weight to the hypothesis that $\alpha \mathrm{CD} 40$ can transform the immunosuppressive pancreatic TME, improving sensitivity to immune checkpoint blockade therapy.

\section{RESULTS}

\section{The orthotopic Pan02 model of pancreatic cancer is insensitive to immune checkpoint blockade therapy but sensitive to $\alpha \mathrm{CD} 40$}

A syngeneic orthotopic pancreatic tumour model was developed whereby Pan02 cells were implanted surgically into the pancreas tail of immunocompetent mice. Orthotopic Pan02 tumours diffusely invaded into the normal pancreas and metastasised to the peritoneal cavity. Primary tumours had a dense desmoplastic stroma highly infiltrated with macrophages (data not shown). We found that orthotopic Pan02 tumour-bearing mice responded poorly to gemcitabine, PD-L1 blockade and CTLA-4 blockade (Figure 1A-1C, study outlines in Supplementary Figure S1A). This allowed us to investigate whether $\alpha \mathrm{CD} 40$ could increase sensitivity to PD-L1 blockade in this model.

In contrast to the minimal effects of immune checkpoint blockade, we found that a CD40 agonist antibody, FGK4.5, led to a significant reduction in early tumour growth and peritoneal metastatic spread (day 29) as measured by endpoint imaging of a luciferaseoverexpressing Pan02 tumour cell line (Pan02-cag-luc2; Figure 1D, study outline in Supplementary Figure S1B). Using a standardised palpation scoring system to measure tumour growth (Supplementary Figure S2), we found that $\alpha \mathrm{CD} 40$ significantly delayed tumour growth of both wild type Pan02 (Figure 1E) and Pan02-cag-luc2 tumours (Supplementary Figure S3) and delayed the onset of secondary indicators associated with disease progression (indicators described in Supplementary Figure S2A, data in Supplementary Figure S4). $\alpha$ CD40 also significantly extended overall survival (Figure 1F), in contrast to $\alpha \mathrm{PD}-\mathrm{L} 1$ and $\alpha \mathrm{CTLA} 4$. However, many animals still ultimately succumbed to metastatic disease, suggesting that $\alpha \mathrm{CD} 40$ alone was only partially successful in driving anti-tumour immunity.

\section{aCD40 transforms the TME}

We next investigated the effects of $\alpha \mathrm{CD} 40$ on the TME in Pan02 tumour-bearing mice. Pan02 tumour-bearing mice were treated with $\alpha \mathrm{CD} 40$ (3mg/kg, once weekly from 
day 7 post-implantation). In separate studies (outlined in Supplementary Figure S1C), tumours were collected for immunohistochemistry at an early timepoint (day 22, 24h after third dose of $\alpha \mathrm{CD} 40$ ), and at a later timepoint for mRNA and protein analysis (day 29, 24h after the last dose of $\alpha \mathrm{CD} 40$ ).

We found that $\alpha \mathrm{CD} 40$ caused a marked change in overall tumour morphology even at an early time-point (day 22). Isotype treated tumours were invasive, diffusely infiltrating the surrounding normal pancreas (Figure 2A). In contrast, $\alpha \mathrm{CD} 40$ treated tumours were surrounded by a dense fibrous capsule with a marked inflammatory response, separating the tumour from the normal pancreas (Figure 2A). This inflammatory capsule contained both $\mathrm{F} 4 / 80^{+}$macrophages and $\mathrm{CD}^{+} \mathrm{T}$ cells (Figure 2A). Whilst there was some $\mathrm{CD}^{+}$cytotoxic $\mathrm{T}$ cell infiltrate in isotype treated tumours, this was also significantly enhanced in $\alpha C D 40$-treated animals (Figure 2B, 1.46 fold increase versus isotype control, $p=0.038)$. In contrast, $\alpha \mathrm{CD} 40$ did not significantly change the number of tumour infiltrating FoxP3 $3^{+} \mathrm{T}_{\text {reg }}$ (Figure 2C). There was therefore a trend toward an improved ratio of $\mathrm{CD}^{+}: \mathrm{FoxP}^{+}$cells
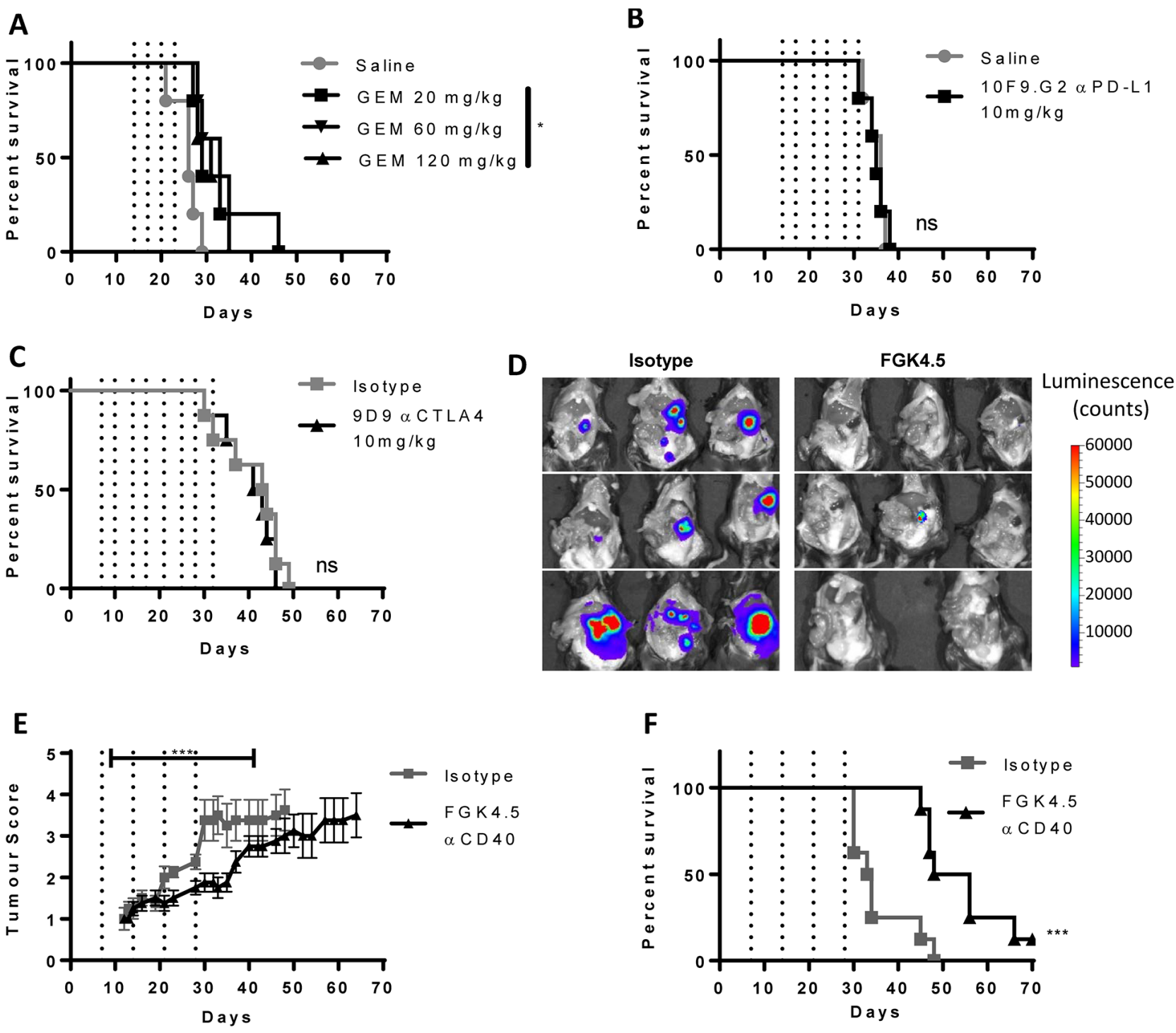

Figure 1: Orthotopic Pan02 model of pancreatic cancer is insensitive to immune checkpoint blockade therapy A-C. Effect of gemcitabine (A,GEM, days 14, 17, 20 and 23), $\alpha$ PD-L1 (B, 10F.9G2, $10 \mathrm{mg} / \mathrm{kg}$, days 14, 17, 21, 24, 28 and 31) and $\alpha \mathrm{CTLA} 4$ $(\mathrm{C}, 9 \mathrm{D} 9,10 \mathrm{mg} / \mathrm{kg}$, days $7,11,14,18,21,25,28,32)$ on overall survival in the orthotopic Pan02 model. $\mathrm{n} \geq 5$ mice per group. *p $<0.05$, ns not significant v.s isotype or saline control, log-rank Mantel-Cox test. D. Effect of CD40 agonist antibody FGK4.5 (i.p. 3 mg/kg, days 7, 14 , 21,28 ) on tumour burden at day 29 in Pan02-cag-luc2 tumour-bearing mice assessed in the exposed peritoneal cavity by bioluminescence imaging. E. Effect of FGK4.5 on tumour volume (blinded palpation scoring, see Supplementary Figure S2) of Pan02 tumour-bearing mice. Data are mean \pm s.e.m. of $\mathrm{n}=8$ animals per group. ${ }^{* * *} \mathrm{p}<0.001$, statistical permutation test versus isotype control (see materials and methods for details). F. Overall survival of Pan02 tumour-bearing mice treated with $3 \mathrm{mg} / \mathrm{kg}$ FGK 4.5 or isotype control. $\mathrm{n}=8$ animals per group **** $<<0.0001$ v.s isotype control, log-rank Mantel-Cox test. 

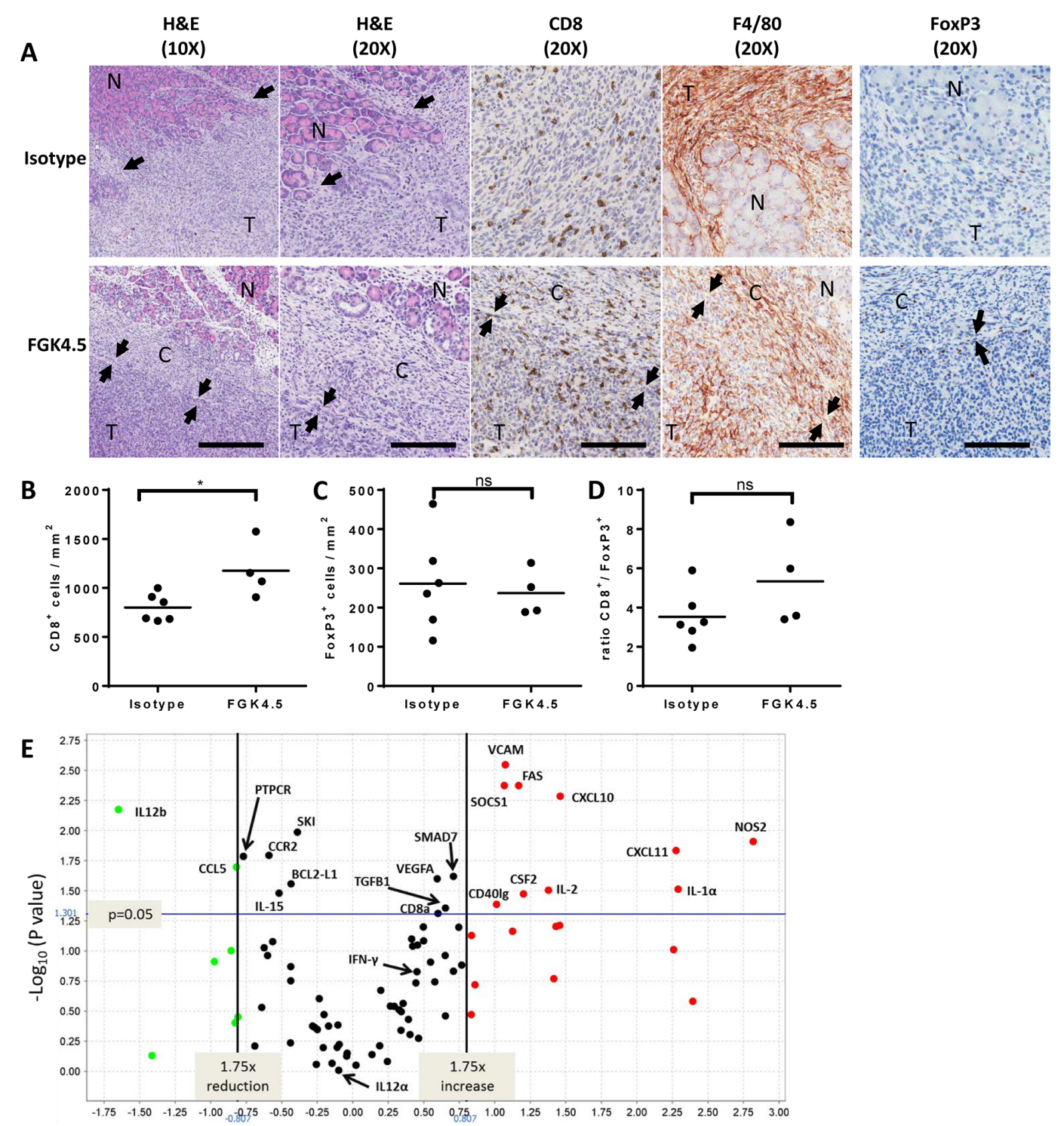

$\log _{2}$ (Fold Change)
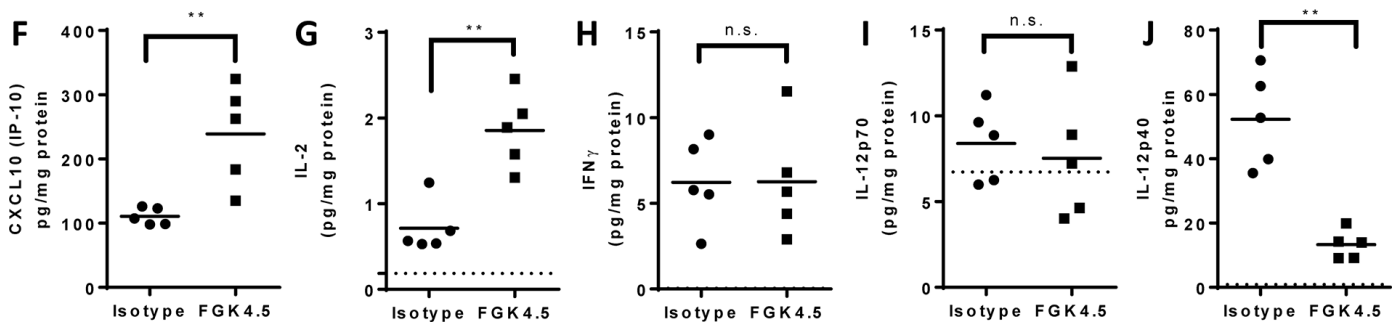

Figure 2: $\boldsymbol{\alpha C D} 40$ transforms the TME A. Effect of FGK4.5 (3 mg/kg, day 7, 14, 21) on orthotopic Pan02 TME on day 22 was assessed by H\&E staining, CD8, F4/80 and FoxP3 immunohistochemistry (IHC). Pan02 tumours (T) were highly invasive in isotype treated mice (top panels), and displayed multiple foci of invasion (arrows) into and destruction of the normal (N) recipient pancreas. In FGK4.5 treated mice (lower panels), tumours were encapsulated and separated from the normal pancreas (N) by a dense fibrous capsule (C) containing abundant inflammatory infiltrates. Arrows denote the clear border between the capsule (C) and the adjacent tumour (T). 10X scale bar $=100 \mu \mathrm{m}, 20 \mathrm{X}$ scale bar $=200 \mu \mathrm{m}$. Images were captured from $10 \mathrm{X}$ Aperio ${ }^{\mathrm{TM}}$ scans or $20 \mathrm{X}$ scans (IHCs). B-D. Quantification of effect of FGK4.5 on $\mathrm{CD}^{+}(\mathrm{B}), \mathrm{FoxP}^{+}(\mathrm{C})$ and ratio of $\mathrm{CD}^{+} / \mathrm{FoxP}^{+} \mathrm{T}$ cells (D) in Pan02 tumours on day 22 . $\mathrm{n} \geq 4$ animals per group, ${ }^{*} \mathrm{p}<0.05$, ns not significant, Mann-Whitney test. E. Mean fold change in mRNA for immune-related genes in FGK4.5 treated Pan02 tumours $(3 \mathrm{mg} / \mathrm{kg}$ day $7,14,21,28)$ versus isotype treated tumours on day 29 . mRNA expression quantified using a Taqman mouse immune array and normalised to six housekeeping genes. $\mathrm{n} \geq 5$ animals group. F-J. ELISA quantification of CXCL10 (F), IL-2 (G), IFN $\gamma$ (H), IL-12p70 (I), and IL-12p40 (J) protein levels in Pan02 tumours on day 29 from mice treated with FGK4.5 $(3 \mathrm{mg} / \mathrm{kg}$, day 7, 14, 21, 28) or isotype control antibody. $\mathrm{n} \geq 5$ animals per group. ${ }^{* *} \mathrm{p}<0.01$, Mann-Whitney test. 
in $\alpha \mathrm{CD} 40$-treated tumours (Figure 2D, 1.51 fold increase versus isotype, $\mathrm{p}=0.114$ ).

Analysis of immune mediator expression in Pan02 tumours at day 29 revealed that $\alpha$ CD40 significantly upregulated the Th1 chemokine CXCL10 at the mRNA (Figure 2E) and protein (Figure 2F) level in Pan02 tumours, along with IL-2 (Figure 2E, 2G), perhaps explaining the expansion or increased infiltration of tumour $\mathrm{CD}^{+} \mathrm{T}$ cells. The Th1 mediators IFN $\gamma$ (Figure 2E, $2 \mathrm{H}$ ) and IL-12p70 (Figure 2I) were unchanged. Different effects were observed on the two subunits of IL-12p70 (IL12p35 / IL12A and IL-12p40 / IL12B). Whilst IL-12p35 expression was unchanged (Figure 2E), expression of IL12 p40 was significantly downregulated by $\alpha$ CD40 at both the mRNA and protein level (Figure 2E, 2J). This may have led to a reduction in levels of IL-12p40 homodimers which can antagonise IL-12p70 effects [30]. aCD40induced changes in tumour inflammatory mediators IL-1 $\alpha$, RANTES (CCL5) and GM-CSF (CSF2) at the mRNA level (Figure 2E) did not translate into significant increases in protein expression (data not shown). Thus, aCD40 significantly altered the TME, enhancing $\mathrm{CD}^{+}$ $\mathrm{T}$ cell infiltration, promoting encapsulation of tumours by an immune infiltrate, and driving a partial Th1 shift in the cytokine / chemokine milieu.

\section{$\alpha C D 40$ drives myeloid cell maturation and memory $T$ cell expansion in spleen}

In order to investigate the effects of $\alpha \mathrm{CD} 40$ on the systemic immune system, Pan02 tumour-bearing mice were treated with $\alpha \mathrm{CD} 40$ (once weekly from day 7 post implantation, four doses). Mice were sacrificed $24 \mathrm{~h}$ after the final dose of $\alpha \mathrm{CD} 40$ (day 29, study outline Supplementary Figure S1C), and splenic myeloid and $\mathrm{T}$ cell populations were characterised by flow cytometry (Figure 3, and Supplementary Figure S5). Three principal groups of splenic myeloid cells were defined based on F4/80, CD11b and Gr-1 expression (Figure 3A). The $\mathrm{CD}_{11 \mathrm{~b}}{ }^{+} / \mathrm{Gr}-1^{-}$gate captures multiple splenic myeloid cell populations including monocytes, macrophages and

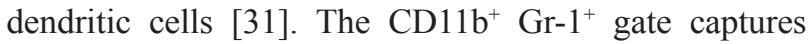
immunosuppressive myeloid-derived suppressor cells, as well as inflammatory monocytes and neutrophils

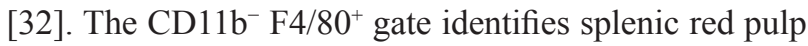
macrophages involved in senescent red blood cell clearance [33]. Only small changes were observed in the proportions of splenic myeloid cells from mice treated with $\alpha \mathrm{CD} 40$ (Supplementary Figure S5A-S5C). However, aCD40 treatment induced a marked increase in the expression of markers of mature antigen presenting cells on these cell populations (Figure 3B-3G, Supplementary Figure S5D$\mathrm{S} 5 \mathrm{~K}$ ), suggesting a change in the differentiation status of splenic myeloid cells. The dendritic cell marker CD11c was upregulated on both $\mathrm{F}_{480}{ }^{+}$and $\mathrm{CD} 11 \mathrm{~b}^{+}$cell populations (Figure 3B, 3C). Induction of MHCI, MHCII, and of the co-stimulatory molecules CD80 and CD86 was also observed broadly on all myeloid populations (Figure 3D$3 \mathrm{G}$, Supplementary Figure S5D-S5K). The only exception to this general trend was a slight downregulation of MHCI

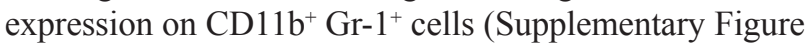
$\mathrm{S} 5 \mathrm{H})$. In addition, $\alpha \mathrm{CD} 40$ treated mice showed expansion of FoxP3 $3^{+} \mathrm{T}_{\text {reg }}$ and $\mathrm{CD}^{+}$cytotoxic T cells (Figure 3I, 3J), and of memory subsets of both $\mathrm{CD}^{+}$and $\mathrm{CD}^{+} \mathrm{T}$ cells (Figure $3 \mathrm{~K}-3 \mathrm{O}$ ). Thus, $\alpha \mathrm{CD} 40$ drove maturation of splenic myeloid cells towards an antigen presenting cell phenotype, and expansion of $\mathrm{T}_{\text {reg }}$ and memory $\mathrm{CD}^{+}$and $\mathrm{CD}^{+} \mathrm{T}$ cells. These data are consistent with $\alpha \mathrm{CD} 40$ driving systemic immune activation, in addition to transforming the TME.

\section{aCD40 upregulates PD-L1 in tumour and spleen}

Since induction of PD-L1 expression was reported to mediate acquired resistance to $\alpha \mathrm{CD} 40$ in breast tumour models [34], we next investigated whether $\alpha \mathrm{CD} 40$ induced PD-L1 and PD-1 expression in the orthotopic Pan02 model. 24h after the last dose of $\alpha$ CD40 (day 29, study outline in Supplementary Figure S1C), tumour PDL1 expression was quantified by qPCR, and splenocyte PD-L1 and PD-1 expression was quantified by flow cytometry. $\alpha \mathrm{CD} 40$ upregulated PD-L1 mRNA expression in Pan02 tumours (Figure 4A, mean 2.1 fold increase in expression, $\mathrm{p}<0.01$ versus isotype). In the spleen, $\alpha \mathrm{CD} 40$

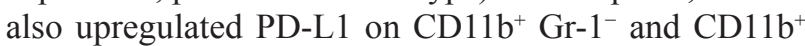
Gr- $1^{+}$myeloid cells (Figure 4B, 4C). Furthermore, PD-1 expression was induced by $\alpha \mathrm{CD} 40$ on splenic $\mathrm{CD}^{+}$ FoxP3 $^{-}$(Figure 4D) and $\mathrm{CD}^{+}$(Figure 4E) effector T cells, but not on $\mathrm{CD}^{+}$FoxP3 $^{+} \mathrm{T}_{\text {reg }}$ (data not shown).

\section{$\alpha \mathrm{CD} 40+\alpha \mathrm{PD}-\mathrm{L} 1$ combination improves anti-tumour immunity}

Because anti-CD40 treatment increased $\mathrm{CD}^{+} \mathrm{T}$ cell infiltration and also upregulation of PD-1 and PD-L1, we tested the hypothesis that a combination of $\alpha \mathrm{CD} 40$ and $\alpha \mathrm{PD}-\mathrm{L} 1$ would induce systemic anti-tumour immunity in this model. Pan02 tumour-bearing mice were treated with aCD40 (3 mg/kg, once weekly from day 7, four doses) and $\alpha$ PD-L1 (10 mg/kg, twice weekly from day 7, six doses), and monitored for tumour growth and overall survival (study outline Supplementary Figure S1D). Primary tumour and peritoneal metastatic tumour burden was quantified for all animals at endpoint. Following on from an initial study running for 84 days, a second, extended study was performed to evaluate long term survival out to 6 months. When PD-L1 blockade was initiated at day 7 (Figure 5A) rather than day 14 (Figure 1C, compare study outlines in Supplementary Figure S1A and S1D), a minimal improvement in overall survival was observed (Figure 5A). The combination of $\alpha \mathrm{CD} 40$ and $\alpha \mathrm{PD}-\mathrm{L} 1$ significantly increased overall survival in comparison to either treatment alone (Figure 5A, $\mathrm{p}<0.0001$ versus 
isotype control or $\alpha \mathrm{PD}-\mathrm{L} 1, \mathrm{p}<0.05$ versus FGK4.5). In the second, extended study $75 \%$ animals treated with this combination survived for 6 months after tumour implantation (Figure 5B). A larger proportion of the animals in the combination group were tumour free at endpoint by examination of the abdominal cavity after sacrifice (Figure 5B), and by quantification of dissected primary and metastatic tumour burden (Figure 5C, 5D). In order to investigate whether $\alpha \mathrm{CD} 40 / \alpha \mathrm{PD}-\mathrm{L} 1$ treatment had induced a systemic anti-tumour immune response, animals treated with these agents individually or in combination were sacrificed $24 \mathrm{~h}$ after the last dose of $\alpha \mathrm{CD} 40$, and splenocytes were re-stimulated with Pan02 cells. An increased number of Pan02-reactive
A
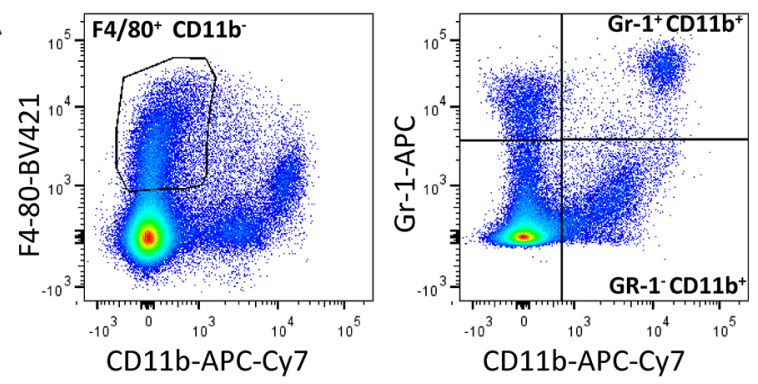
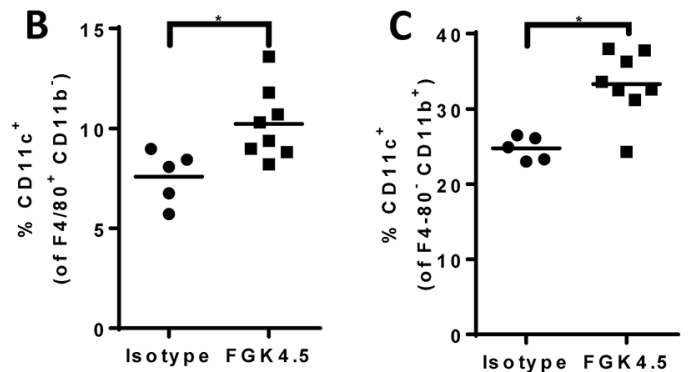
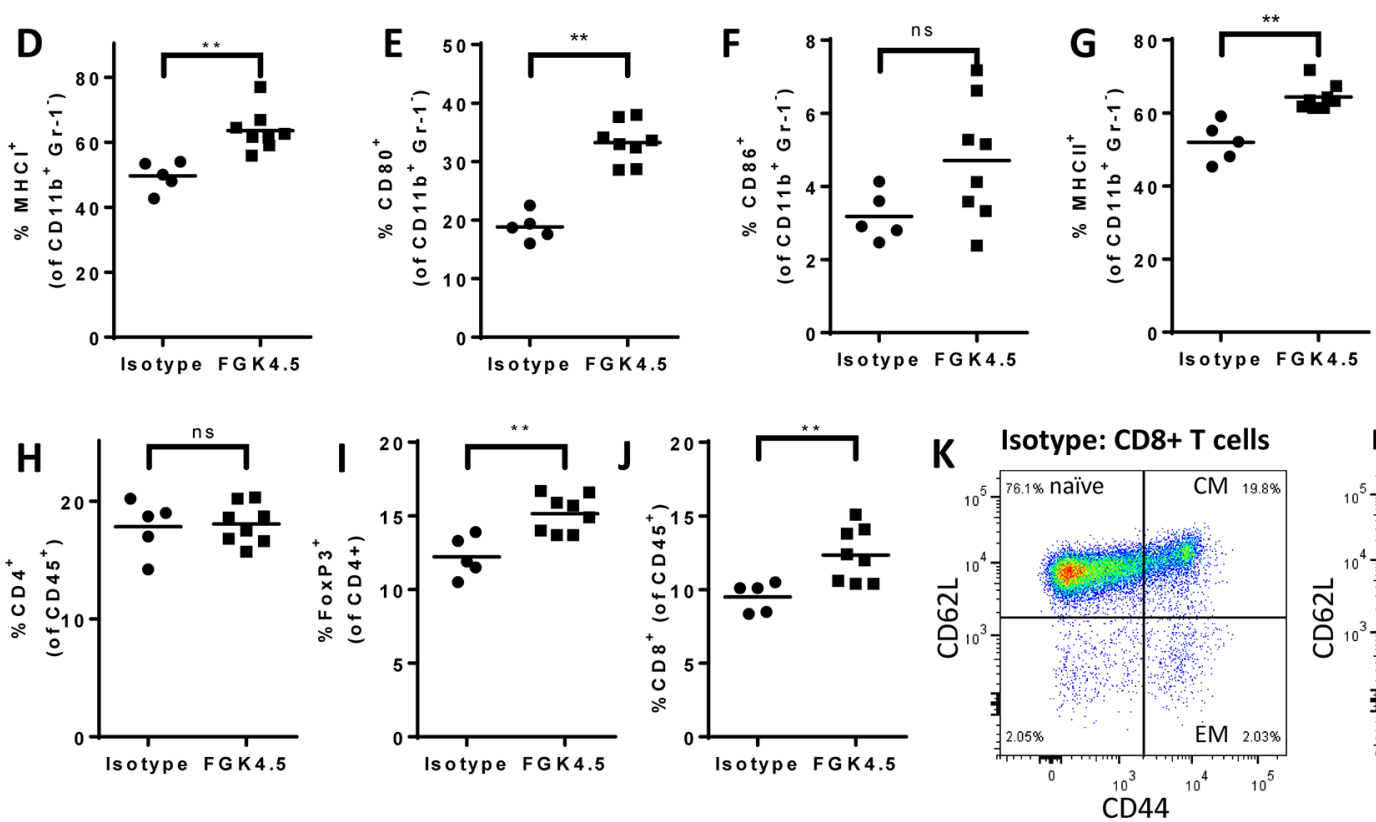

FGK4.5: CD8+ T cells
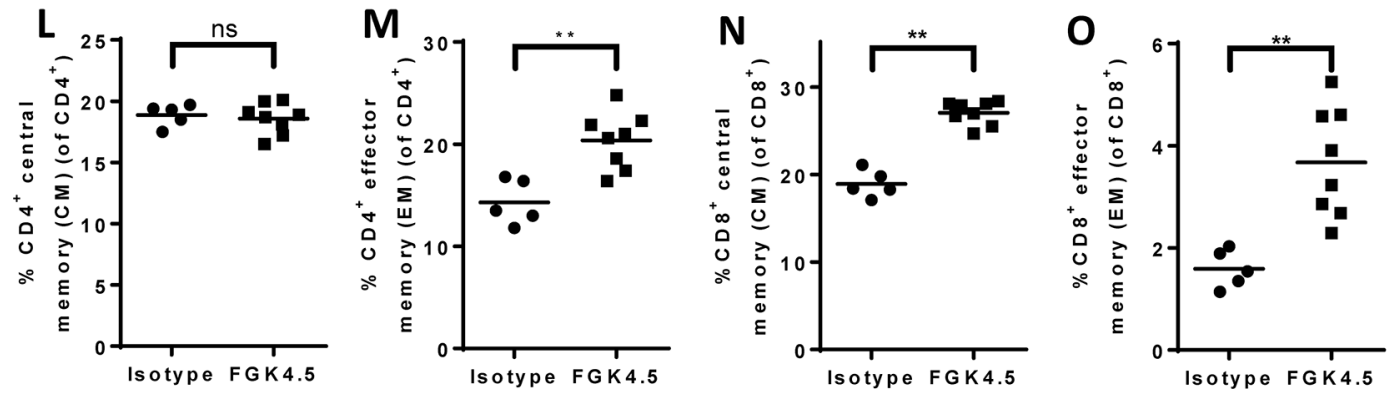

Figure 3: aCD40 drives myeloid cell maturation and memory $T$ cell expansion in spleen A. Gating strategy for identification of $\mathrm{F} 4 / 80^{+} \mathrm{CD}_{11 \mathrm{~b}^{-}}$(left panel), CD11 $\mathrm{b}^{+} \mathrm{Gr}-1^{-}$and $\mathrm{CD} 11 \mathrm{~b}^{+} \mathrm{Gr}-1^{+}$(right panel) myeloid cells in splenocytes from Pan02 tumour-bearing mice. B, C. Effect of FGK4.5 treatment (i.p. $3 \mathrm{mg} / \mathrm{kg}$ day 7, 14, 21, 28, endpoint 24h after last dose) on CD11c expression in splenic F4/80 $\mathrm{CD}_{11 \mathrm{~b}}{ }^{-}(\mathrm{B})$ and $\mathrm{F} 4 / 80^{-} \mathrm{CD} 11 \mathrm{~b}^{+}$(C) myeloid cells. D-G. Effect of FGK4.5 on splenic CD11 b $\mathrm{b}^{+} \mathrm{1}^{-}$myeloid cell expression of MHCI (D), CD80 (E), CD86 (F) and MHCII (G). H-J. Effect of FGK4.5 treatment on the proportions of total CD4 ${ }^{+}(\mathrm{H}), \mathrm{CD}^{+} \mathrm{FoxP}^{+}$(I) and CD8 ${ }^{+}$ (J) T cells in Pan02 tumour-bearing mouse spleens. K. Example data showinggating strategy fornaïve, CM and EM spenic CD8 ${ }^{+} \mathrm{T}$ cell populations in splenocytes from animals treated with isotype (left panel) or FGK4.5 (right panel). L-O. Effect of FGK4.5 treatment on the proportions of $\mathrm{CD}^{+}(\mathrm{L}, \mathrm{M})$ and $\mathrm{CD}^{+}(\mathrm{N}, \mathrm{O})$ cells with a central memory $\left(\mathrm{CM}, \mathrm{CD}_{4} 4^{+} \mathrm{CD} 62 \mathrm{~L}^{+}, \mathrm{L}, \mathrm{N}\right)$ or effector memory $\left(\mathrm{EM}, \mathrm{CD} 44^{+}\right.$ CD62L $\left.\mathrm{L}^{-}, \mathrm{M}, \mathrm{O}\right)$ phenotype. $\mathrm{n} \geq 5$ animals per group. ${ }^{* *} \mathrm{p}<0.01,{ }^{*} \mathrm{p}<0.05$ Mann-Whitney test. 

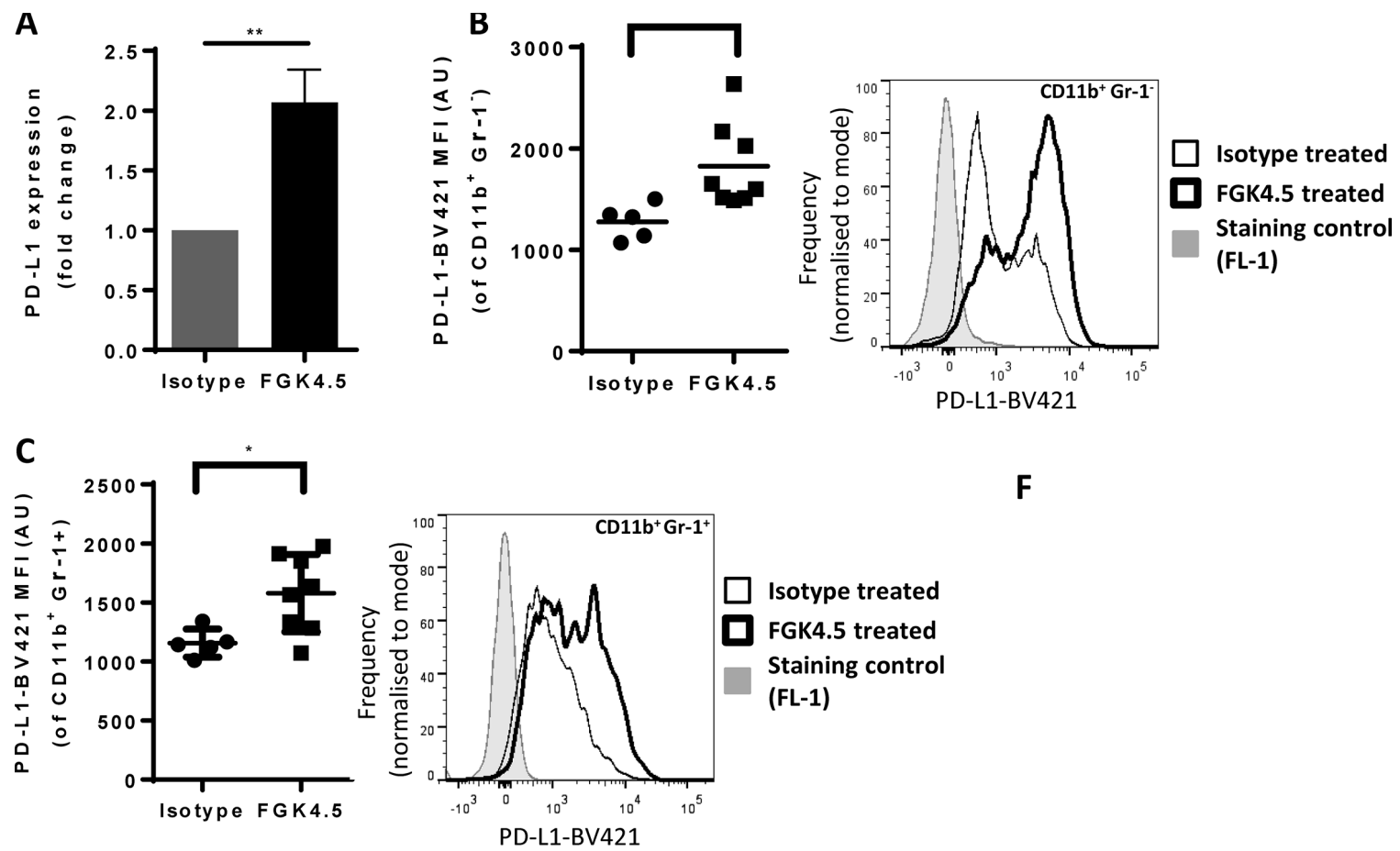

$\mathbf{F}$
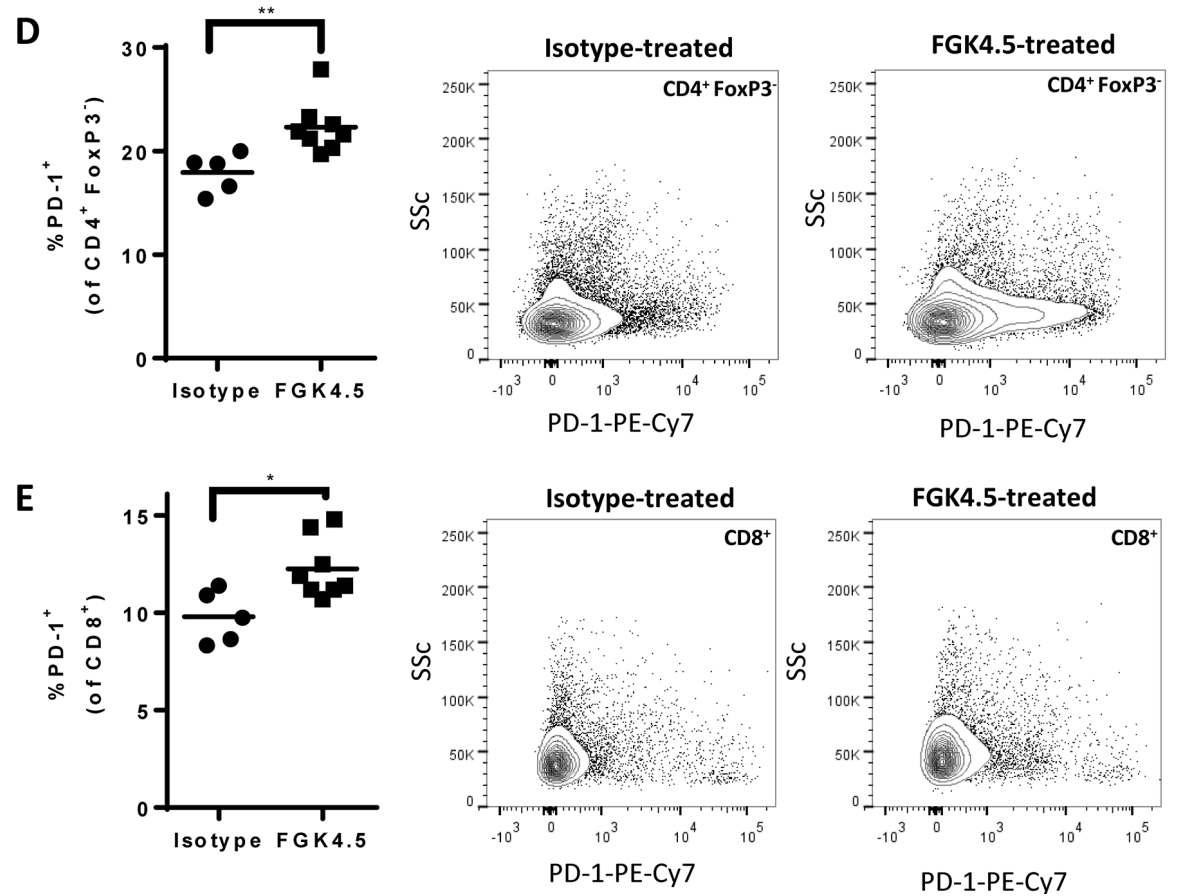

Figure 4: $\boldsymbol{\alpha C D 4 0}$ upregulates PD-L1 in tumour and spleen A. Effect of FGK4.5 treatment (i.p. 3 mg/kg day 7, 14, 21, 28, endpoint day 29) on PD-L1 mRNA expression in Pan02 tumours. Data shown are fold change in expression versus isotype treated tumours, with expression levels normalised to the housekeeping gene Hprt. Data are mean \pm s.e.m of $n \geq 5$ animals per group **p $<0.01$ Mann-Whitney test. B, C. Effect of FGK4.5 treatment on PD-L1 expression on CD11b $\mathrm{Gr}^{-} 1^{-}$(B) and CD11 b $\mathrm{Gr}^{+} 1^{+}$(C) myeloid cells in spleen. Scatter plots (left panel) show geometric mean fluorescence intensity of cells stained with PD-L1-BV-421 from individual mice. Histograms (right panel) show example PD-L1 staining in splenocytes from a representative animal treated with FGK4.5 (thick line) or isotype (thin line) in comparison to fluorescence minus 1 (FL-1) staining control (shaded histogram). $\mathrm{n} \geq 5$ animals per group ${ }^{* *} \mathrm{p}<0.01,{ }^{*} \mathrm{p}<0.05$ Mann-Whitney test. D-F. Effect of FGK4.5 on PD-1 expression on CD4 $4^{+}$FoxP3 ${ }^{-}$(D) and CD8 ${ }^{+}$(E) T cells in spleen. Scatter plots (left panel) show \% PD-1 positive cells from individual animals. Contour plots (centre and right panels) show PD-1 staining in splenocytes from a representative animal treated with isotype (centre panel) or FGK4.5 (right panel). $\mathrm{n} \geq 5$ animals per group $* * \mathrm{p}<0.01,{ }^{*} \mathrm{p}<0.05$ Mann-Whitney test. 
A

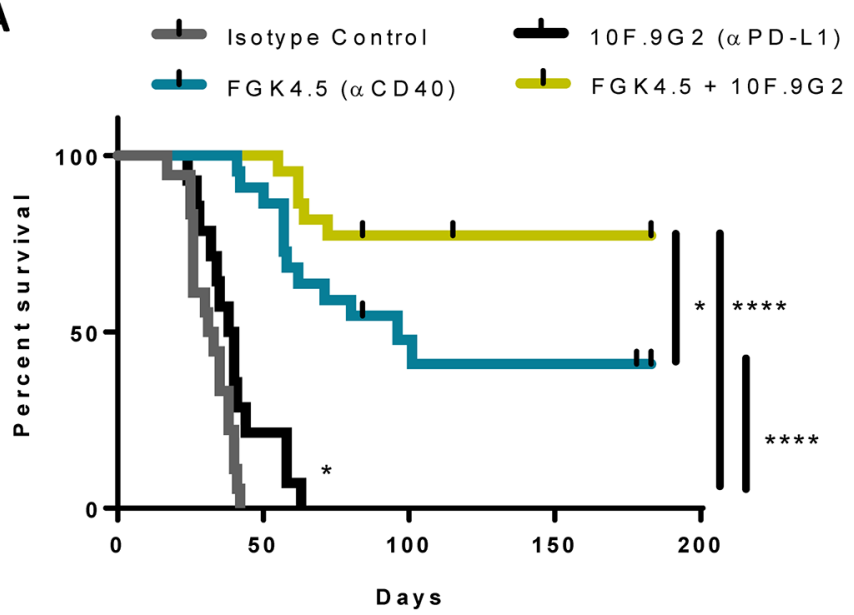

B

\begin{tabular}{|l|c|c|}
\hline \multirow{2}{*}{ Treatment } & \multicolumn{2}{|c|}{$\begin{array}{c}\text { Tumour free at study end } \\
\text { (\%) }\end{array}$} \\
\cline { 2 - 3 } & $\begin{array}{c}\text { Study 1 } \\
\text { (day 84) }\end{array}$ & $\begin{array}{c}\text { Study 2 } \\
\text { (day 183) }\end{array}$ \\
\hline Isotype & $0 / 10(0 \%)$ & $0 / 8(0 \%)$ \\
\hline $10 F .9 G 2$ & $0 / 6(0 \%)$ & $0 / 8(0 \%)$ \\
\hline FGK4.5 & $2 / 10(20 \%)$ & $6 / 12(50 \%)$ \\
\hline FGK4.5+ 10F.9G2 & $5 / 10(50 \%)$ & $9 / 12(75 \%)$ \\
\hline
\end{tabular}

C

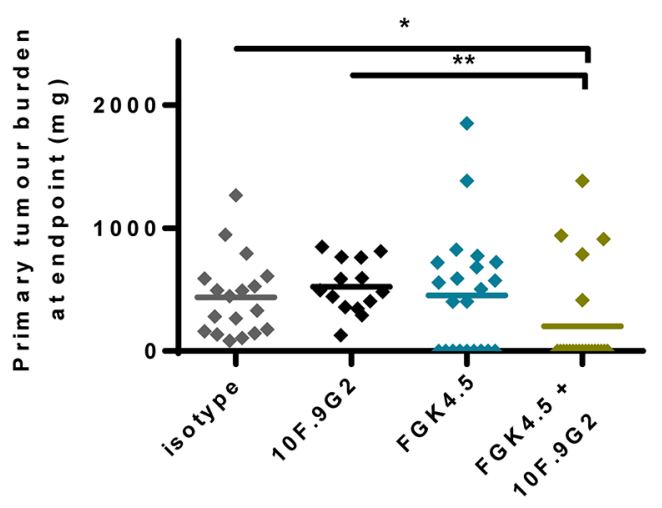

$\mathbf{E}$

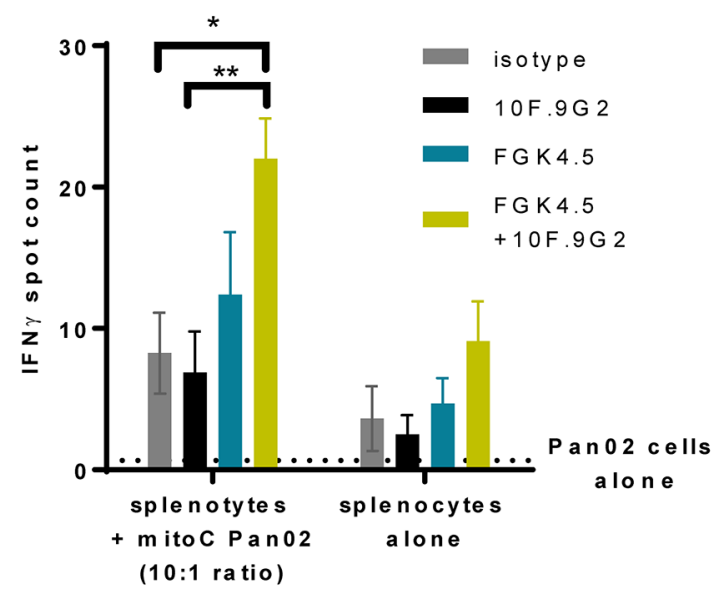

D

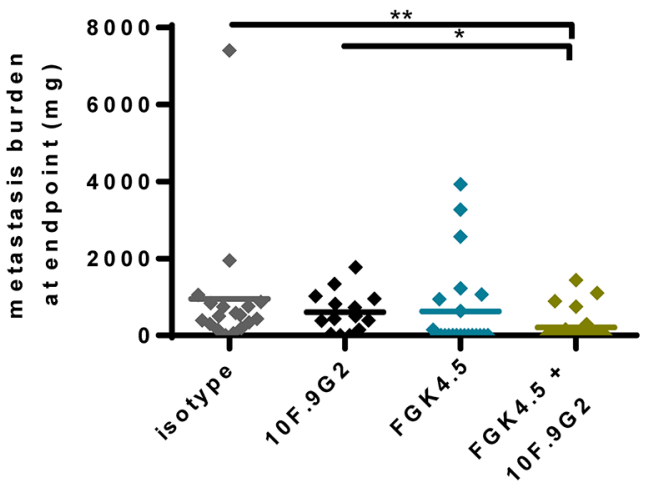

Figure 5: $\boldsymbol{\alpha C D 4 0}+\boldsymbol{\alpha P D}-\mathbf{L} 1$ combination improves anti-tumour immunity A. Effect of FGK4.5 (i.p. $3 \mathrm{mg} / \mathrm{kg}$ days 7, 14, 21, 28) and 10F.9G2 (i.p. $10 \mathrm{mg} / \mathrm{kg}$ days 7, 10, 14, 17, 21, 24) on the overall survival of mice bearing Pan02 tumours. Data are compiled from $\mathrm{n}=2$ independent experiments with a total of $\mathrm{n} \geq 14$ animals per group.**** ${ }^{*}, 0.0001,{ }^{*} \mathrm{p}<0.05, \log$-rank Mantel-Cox test. B. Proportion of mice that were tumour free at study end for $n=2$ independent studies. C, D. Quantification of Pan02 primary tumour burden (C) and metastasis burden (D) at endpoint. $\mathrm{n} \geq 14$ animals per group from $\mathrm{n}=2$ independent experiments. ${ }^{* *} \mathrm{p}, 0.01,{ }^{*} \mathrm{p}<0.05$, Kruskal-Wallis with post-hoc Dunn's multiple comparison test. E. Quantification of the effects of FGK4.5 and 10F.9G2 on the number of IFN $\gamma$ positive splenocytes following in vitro re-stimulation with Pan02 cells. Data are mean \pm s.e.m. of $\mathrm{n} \geq 4$ animals per group, ${ }^{* *} \mathrm{p}<0.01,{ }^{*} \mathrm{p}<0.05$, Two way ANOVA with post hoc Sidak's multiple comparisons test. 
splenocytes were detected by IFN $\gamma$ ELISPOT assay in animals treated with the combination of $\alpha \mathrm{CD} 40$ and $\alpha \mathrm{PD}-\mathrm{L} 1$ (Figure 5E). Taken together, these data indicate that $\alpha \mathrm{CD} 40$ combination with $\alpha \mathrm{PD}-\mathrm{L} 1$ enhanced systemic anti-tumour immunity in the orthotopic Pan02 model.

\section{DISCUSSION}

We report here that a CD40 agonist antibody transformed the TME and promoted systemic anti-tumour immune activation in a mouse orthotopic pancreatic tumour model, Pan02. $\alpha$ CD40 treatment improved overall survival as a single agent, and increased sensitivity to PD-L1 blockade, leading to long term survival and enhanced anti-tumour immunity. Our data build on previous reports that $\alpha \mathrm{CD} 40$ increased sensitivity to immune checkpoint blockade in mouse pancreatic (s.c. transplantable and spontaneous KPC) and breast tumour models [27, 34]. We demonstrate the effects of this combination in a pancreatic orthotopic tumour model and provide further insight into the mechanism by which $\alpha \mathrm{CD} 40$ improves sensitivity to $\alpha \mathrm{PD}-\mathrm{L} 1$.

We found that orthotopic Pan02 tumour-bearing mice were resistant to PD-L1 and CTLA-4 blockade. However, $\mathrm{CD} 8^{+}$cytotoxic T cells were not excluded from isotype treated Pan02 tumours, suggesting that Pan02 tumour-infiltrating $\mathrm{CD} 8^{+} \mathrm{T}$ cells are either naïve or have become inactivated. Both exclusion of effector T cells from tumours and inactivation of tumour infiltrating $\mathrm{T}$ cells have been proposed to be responsible for the failure of some patients to respond to immune checkpoint blockade [4]. CD8 ${ }^{+} \mathrm{T}$ cells are excluded from many pancreatic cancer patient tumours, and from KPC mice with spontaneous pancreatic tumours $[14,15]$. However, in pancreatic cancer patients where $\mathrm{CD}^{+} \mathrm{T}$ cell infiltration in tumours is observed, $\mathrm{CD} 8^{+} \mathrm{T}$ cells become inactivated through loss of $\mathrm{CD} 3 \zeta$ [14].

Multiple effector mechanisms have previously been reported to contribute to $\alpha \mathrm{CD} 40$-mediated inhibition of tumour growth and metastasis. $\alpha \mathrm{CD} 40$ can induce both $\mathrm{T}$ cell-independent anti-tumour effects, enhancing macrophage tumouricidal activity and stromal remodelling, and $\mathrm{CD} 8^{+} \mathrm{T}$ cell-dependent antitumour immunity [35]. Our data are more consistent with $\alpha \mathrm{CD} 40$ having induced both innate and adaptive immune activation in Pan02 tumour-bearing mice to improve overall survival. Treatment with a CD40 agonist antibody drove the formation of a dense capsule rich in cytotoxic $\mathrm{T}$ cells and macrophages that separated the pancreatic tumour from the normal pancreas. Furthermore, $\alpha \mathrm{CD} 40$ upregulated IL-2 and the Th1 T cell chemokines, CXCL10 and CXCL11, and increased CD $8^{+}$ $\mathrm{T}$ cell infiltration and tumour PD-L1 expression. Our finding that $\alpha \mathrm{CD} 40$ induced an increase in $\mathrm{CD} 8^{+}$cells in orthotopic Pan02 tumours is in accord with data reported by Zippelius et al. [34] in s.c. MC38 breast tumours. $\alpha \mathrm{CD} 40$ also drove systemic innate immune activation
(APC maturation), and expanded central and effector memory cytotoxic $\mathrm{T}$ cells.

The majority of $\alpha \mathrm{CD} 40$-treated animals developed progressive disease, indicating that $\alpha \mathrm{CD} 40$-induced adaptive immune activation was insufficient. Our data suggest that upregulation of the PD-L1 / PD-1 immune checkpoint, both in the TME and systemically on myeloid cells, contributes to the failure of this adaptive immune response. Thus, whilst PD-L1 blockade alone had minimal effects on overall survival, combining CD40 agonism with PD-L1 blockade improved overall survival in comparison to either monotherapy alone.

PD-L1 upregulation on tumour cells (including Pan02 cells) and myeloid cells can be induced by IFN $\gamma[6$, 28]. However, we did not observe any increase in IFN $\gamma$ in the TME with $\alpha \mathrm{CD} 40$ treatment. It is possible that IFN $\gamma$ induction occurred at an earlier time point and had since returned to baseline. Alternatively, PD-L1 may have been induced via an IFN $\gamma$-independent pathway in this model [36-38].

Survival times for pancreatic cancer patients treated with even the more recently developed chemotherapy regimens (FOLFIRINOX, or gemcitabine plus nabpaclitaxel) remain poor $[39,40]$. Chemotherapy could theoretically promote anti-tumour immune responses by inducing immunogenic cell death and depleting suppressive immune cells [41-43]. However, it is also possible that the immunosuppressive effects of chemotherapy would limit responses to immunotherapy. In a spontaneous mouse pancreatic tumour model, the addition of gemcitabine did not improve the anti-tumour efficacy of CD40 agonism [25]. This contrasts with an earlier report of the benefits of this combination in less immunosuppressive subcutaneous tumour models [44]. The combination of nab-paclitaxel, gemcitabine and $\alpha \mathrm{CD} 40$ with $\alpha \mathrm{PD}-1$ improved responses versus $\alpha \mathrm{PD}-1$ alone in the KPC model. However, the contribution of chemotherapy to this effect was not investigated [27]. We found that $\alpha \mathrm{CD} 40$ increased sensitivity to PD-L1 blockade in the absence of chemotherapy in an orthotopic pancreatic tumour model. A similar combination effect in the absence of chemotherapy was also observed in breast tumour models [34]. Thus the potential benefits of adding chemotherapy to a combination with $\alpha \mathrm{CD} 40$ and $\alpha \mathrm{PD}-\mathrm{L} 1$ treatment remain unresolved.

In summary, our data provide further preclinical support for the potential benefits of combining immunotherapies such as $\alpha \mathrm{CD} 40$ that transform the TME with immune checkpoint blockade to promote anti-tumour immunity in pancreatic cancer.

\section{MATERIALS AND METHODS}

\section{Cell lines and reagents}

Pan02 cells, a SMAD4-null chemically induced mouse pancreatic tumour line, was from the National 
Cancer Institute [45, 46]. Pan02-CAG-luc2 cells were generated by lentiviral transduction. Briefly, DNA encoding the luciferase 2 gene (luc2, Promega) was cloned into a lentiviral vector (pCDH-CAG-IRES-puro, System Biosciences). Lentivirus was generated using the pPack lentiviral packaging system (SBI), and used to transduce Pan02 cells. Following antibiotic selection, a pool of stably transduced cells (Pan02-CAG-luc2) was obtained and used for in vivo studies. Luc2 expression in the Pan02CAG-luc2 cell line pool was stable up to passage 16 , as determined by luciferase assay (Promega, data not shown).

The following antibodies from eBioscience, BD Bioscience and Biolegend were used for flow cytometry: anti-CD45 (clone 30-F11), anti-CD44 (clone IM7), antiCD62L (clone MEL-14), anti-CD3 (clone 145-2C11), antiCD4 (Clone RM4.5), anti-CD8 (clone 53-6.7), anti-F4/80 (clone BM8), anti-MHCI (clone 28-8-6), anti-CD80 (clone 16-10A), anti-CD86 (clone GL-1), anti-MHCII (clone M5/114.15.2), anti-Gr-1 (clone RB6-8C5), anti-CD11b (clone M1/70), anti-CD11c (clone N418), anti-CD19 (clone6D5), anti-PD-L1 (clone 10F.9G2), anti-PD-1 (clone 29F.1A12), anti-FoxP3 (FJK-16S).

\section{Murine syngeneic orthotopic pancreatic Pan02 pancreatic tumour model}

Experiments using 6 - 8 week old female C57BL/6J mice (Charles River) were conducted under a U.K.Home Office Project Licence in accordance with the U.K. Animal (Scientific Procedures) Act 1986 and in accordance with EU Directive EU 86/609. 30 minutes after prophylactic analgesia (buprenorphine, $60 \mu \mathrm{g}$ s.c.), mice were shaved and anaesthetised (isoflurane). 5 x 105 Pan02 or Pan02CAG-luc2 pancreatic tumour cells in chilled matrigel (Corning) were surgically implanted in the pancreas tail [47] and the abdominal wall was closed with dissolvable sutures and autoclips. Clips were removed seven to 10 days after surgery.

Group sizes for tumour growth studies were determined based on existing data for orthotopic Pan02 tumour growth, to test for greater than $45 \%$ tumour growth inhibition. The power calculation was a onesided 2 sample t-test carried out at the $5 \%$ significance level. Animals were randomised to treatment groups based on body weight prior to the first treatment. Due to the technical challenges of in vivo imaging of orthotopic tumours in C57/BL6 mice, we developed and validated a blinded scoring system based on abdominal palpation and animal welfare (Supplementary Figure S2). This incorporates both a score for primary tumour size by abdominal palpation (score of 1-6) and clinical observations (weight loss, tumour attachment to abdominal wall, secondary tumours, abdominal swelling and eschar formation, all adding +1 to overall score). For survival studies, animals were euthanized when either their primary tumour or combined tumour and clinical observation score reached +6 . FGK4.5 CD40 agonistic antibody (rat IgG2a, $3 \mathrm{mg} / \mathrm{kg}, 4$ doses, once weekly from day 7), 9D9 CTLA-4 blocking antibody (mouse IgG2b, $10 \mathrm{mg} / \mathrm{kg}$, day 7, 11, 14, $18,21,25,28,32$ ) and 10F.9G2 PD-L1 blocking antibody (rat IgG2b, $10 \mathrm{mg} / \mathrm{kg}, 6$ doses, twice weekly from day 7 or day 14 as indicated) were from Bio X Cell. All antibodies were dosed intraperitoneally (i.p).

For imaging studies, luciferase expression in Pan02CAG-luc2 tumours was assessed 29 days after cells were implanted. Animals were injected with $3.3 \mathrm{mg}$ of luciferin (Perkin Elmer) i.p., euthanised and the peritoneal cavity exposed. The peritoneal cavity was imaged 20 minutes after luciferin injection on the IVIS100 (Perkin Elmer) with an acquisition time of 10 seconds.

\section{Flow cytometry analysis}

Animals were euthanized and spleens were removed and dissociated to a single cell suspension through a $70 \mu \mathrm{m}$ nylon mesh. Splenocytes were stained with a fixable live dead dye (Life Technologies) followed by block with anti CD16/32 antibody (eBiosciences) and staining with cocktails of fluorescence conjugated antibodies prior to fixation in $1 \%$ formaldehyde / PBS. FoxP3 nuclear staining was carried out on fixed and permeabilised cells (FoxP3 / transcription factor staining buffer set, eBioscience). Stained cells were analysed by flow cytometry (BD LSRFortessa, BD Biosciences) with data analysis in FlowJo (Tree Star). Positive staining gates were identified by comparison to cells stained with the full antibody panel minus the antibody of interest (FL-1 control).

\section{Immunohistochemistry and image analysis}

Tumour samples were harvested, fixed in $10 \%$ neutral buffered formalin, processed and embedded into paraffin wax blocks. Sections were taken at $4 \mu \mathrm{m}$ and then de-waxed, rehydrated and antigen retrieved using either a pressure cooker with low or high $\mathrm{pH}$ buffer (Vector / Dako) or enzymatic retrieval with proteinase K. Sections were then blocked for endogenous peroxidase with $\mathrm{H}_{2} \mathrm{O}_{2}$ in methanol prior to immunostaining. Following a protein/ serum block, sections were immunostained with primary rat monoclonal antibodies to FoxP3 (eBioscience), CD8 (eBioscience) and F4/80 (AbD Serotec) for 1 hour at room temperature. Primary antibodies were detected with goat anti-rat IgG (Jackson ImmunoResearch) followed by anti-goat Ig ImmPRESS-HRP polymer (Vector). CD8 was detected directly with mouse adsorbed anti-rat ImmPRESSHRP polymer (Vector). Staining was then visualised using $\mathrm{DAB}+$ substrate (Dako). Sections were then counterstained with Haematoxylin, dehydrated, cleared and permanently coverslipped. Tissue morphology and collagen were also demonstrated using Haematoxylin \& Eosin and Masson's Trichrome staining respectively. Slides were digitally scanned using an Aperio Scanscope and whole slide image 
analysis was performed in the tumour region only with algorithms created in Definiens Tissue Studio version 4.1.

\section{Tumour mRNA and protein analysis}

Animals were euthanized and pancreatic tumours dissected out from normal pancreas, before being either snap frozen or transferred to RNALater. Snap frozen tumours were homogenised in tissue lysis buffer (100 $\mathrm{mM} \mathrm{NaCl}, 20 \mathrm{mM}$ Tris $\mathrm{pH}$ 7.5, $1 \mathrm{mM}$ EDTA, $1 \mathrm{mM}$ EGTA, $1 \%$ Triton X-100, with complete protease inhibitor cocktail (Roche) and phosphatase inihibitor cocktails II and III (Sigma Aldrich)) using a GentleMACS tissue dissociator (Miltenyi) followed by sonication and clarification of homogenates by centrifugation at 10,000 $\mathrm{g}$ for 10 minutes. Homogenate protein concentrations were quantified by BCA assay (ThermoFisher Scientific). Cytokine and chemokine levels in homogenates and plasma were quantified by multiplex ELISAs according to manufacturer's instructions (Mesoscale Diagnostics, eBioscience).

RNA was extracted from tumours stored in RNALater using RNeasy mini kits (Qiagen), followed by mRNA reverse transcription with multiScribeTM MuLV enzyme (Life Technologies). Chemokine, cytokine and PD-L1 mRNA expression was quantified using a mouse immune gene signature array (Applied Biosystems \#4367786) and a specific PD-L1 Taqman qPCR primer set (Applied Biosystems Mm00452054_m1). qPCR was run on a QuantStudio7 Flex real time PCR system (Applied Biosystems).

\section{Ex vivo splenocyte re-stimulation}

Pan02 cells are MHCI negative (data not shown), and were therefore IFN $\gamma$-treated to upregulate MHCI $(20 \mathrm{ng} / \mathrm{mL}, 24 \mathrm{~h})$, before mitomycin C treatment $(50 \mu \mathrm{g} /$ $\mathrm{mL}, 20 \mathrm{~min}$ ) and extensive washing. $8.3 \times 10^{3} \mathrm{Pan} 02$ cells were co-cultured with $8.3 \times 10^{4}$ disaggregated splenocytes from Pan02 tumour-bearing mice (day 29 post-implantation) in RPMI (Life technologies) with $10 \%$ fetal bovine serum (SAFC Biosciences) and 10 U/mL IL-2 for 96 hours in Multiscreen ${ }_{\text {нтS }}$ IP plates (Millipore) coated with anti-IFN $\gamma$ capture antibody (eBiosciences). The number of IFN $\gamma$-producing T cells was then quantified by ELISPOT assay according to manufacturer's instructions (eBiosciences).

\section{Statistical analysis}

The effect of $\alpha \mathrm{CD} 40$ on tumour growth was analysed using a statistical permutation test comparing tumour growth over the whole course of model progression, using the method of [48] with analysis performed using Statmod (https://cran.r-project.org/web/packages/statmod/index. $\mathrm{html}$ ) in R version 1.4.18. All other statistical analyses were performed in Graphpad Prism v6.03.

\section{ACKNOWLEDGMENTS}

Thanks to Hazel Jones for leading efforts to develop orthotopic tumour model capabilities at MedImmune, to Athula Herath and Robert Kozarski for advice on experimental design and statistical analysis, to Janette Dillon for developing the Pan02 CAG luciferase cell line, to Simon Dovedi and Viia Valge-Archer for critically reviewing the manuscript, and to the biological services unit and core tissue culture facility at MedImmune for technical support.

\section{FUNDING}

This work was funded by MedImmune Ltd.

\section{CONFLICTS OF INTEREST}

All the authors are employees of MedImmune Ltd.

\section{Abbreviations}

aCD40, CD40 agonist antibody; PD-1, programmed cell death protein 1; PD-L1, programmed death ligand 1; CTLA-4, cytotoxic lymphocyte-associated antigen 4; $\mathrm{T}_{\text {reg, }}$, regulatory $\mathrm{T}$ cell; IFN $\gamma$, interferon $\gamma$; KPC, KRAS ${ }^{\mathrm{LSL}-}$ G12D/+ / Trp53 ${ }^{\mathrm{LSL}-\mathrm{R} 172 \mathrm{H} /++} / \mathrm{Pdx}-1-\mathrm{Cre} ;$ i.p., intraperitoneal; s.c., subcutaneous; APC, antigen presenting cell; IHC, immunohistochemistry; tumour microenvironment, TME.

\section{REFERENCES}

1. Mittal D, Gubin MM, Schreiber RD and Smyth MJ. New insights into cancer immunoediting and its three component phases--elimination, equilibrium and escape. Curr Opin Immunol. 2014; 27:16-25.

2. Matsushita H, Vesely MD, Koboldt DC, Rickert CG, Uppaluri R, Magrini VJ, Arthur CD, White JM, Chen YS, Shea LK, Hundal J, Wendl MC, Demeter R, Wylie T, Allison JP, Smyth MJ, et al. Cancer exome analysis reveals a T-cell-dependent mechanism of cancer immunoediting. Nature. 2012; 482:400-404.

3. DuPage M, Mazumdar C, Schmidt LM, Cheung AF and Jacks T. Expression of tumour-specific antigens underlies cancer immunoediting. Nature. 2012; 482:405-409.

4. Motz GT and Coukos G. Deciphering and reversing tumor immune suppression. Immunity. 2013; 39:61-73.

5. Chen DS, Irving BA and Hodi FS. Molecular pathways: next-generation immunotherapy--inhibiting programmed death-ligand 1 and programmed death-1. Clin Cancer Res. 2012; 18:6580-6587.

6. Pardoll DM. The blockade of immune checkpoints in cancer immunotherapy. Nat Rev Cancer. 2012; 12:252-264.

7. Sharma $P$ and Allison JP. The future of immune checkpoint therapy. Science. 2015; 348:56-61. 
8. Brahmer JR, Tykodi SS, Chow LQ, Hwu WJ, Topalian SL, Hwu P, Drake CG, Camacho LH, Kauh J, Odunsi K, Pitot HC, Hamid O, Bhatia S, Martins R, Eaton K, Chen S, et al. Safety and activity of anti-PD-L1 antibody in patients with advanced cancer. N Engl J Med. 2012; 366:2455-2465.

9. Royal RE, Levy C, Turner K, Mathur A, Hughes M, Kammula US, Sherry RM, Topalian SL, Yang JC, Lowy I and Rosenberg SA. Phase 2 trial of single agent Ipilimumab (anti-CTLA-4) for locally advanced or metastatic pancreatic adenocarcinoma. J Immunother. 2010; 33:828-833.

10. Taube JM, Anders RA, Young GD, Xu H, Sharma R, McMiller TL, Chen S, Klein AP, Pardoll DM, Topalian SL and Chen L. Colocalization of inflammatory response with B7-h1 expression in human melanocytic lesions supports an adaptive resistance mechanism of immune escape. Sci Transl Med. 2012; 4:127ra137.

11. Taube JM, Klein A, Brahmer JR, Xu H, Pan X, Kim JH, Chen L, Pardoll DM, Topalian SL and Anders RA. Association of PD-1, PD-1 ligands, and other features of the tumor immune microenvironment with response to anti-PD-1 therapy. Clin Cancer Res. 2014; 20:5064-5074.

12. Tumeh PC, Harview CL, Yearley JH, Shintaku IP, Taylor EJ, Robert L, Chmielowski B, Spasic M, Henry G, Ciobanu V, West AN, Carmona M, Kivork C, Seja E, Cherry G, Gutierrez AJ, et al. PD-1 blockade induces responses by inhibiting adaptive immune resistance. Nature. 2014; 515:568-571.

13. Clark CE, Beatty GL and Vonderheide RH. Immunosurveillance of pancreatic adenocarcinoma: insights from genetically engineered mouse models of cancer. Cancer Lett. 2009; 279:1-7.

14. von Bernstorff W, Voss M, Freichel S, Schmid A, Vogel I, Johnk C, Henne-Bruns D, Kremer B and Kalthoff H. Systemic and local immunosuppression in pancreatic cancer patients. Clin Cancer Res. 2001; 7:925s-932s.

15. Clark CE, Hingorani SR, Mick R, Combs C, Tuveson DA and Vonderheide RH. Dynamics of the immune reaction to pancreatic cancer from inception to invasion. Cancer Res. 2007; 67:9518-9527.

16. Joyce JA and Fearon DT. T cell exclusion, immune privilege, and the tumor microenvironment. Science. 2015; 348:74-80.

17. Le DT, Lutz E, Uram JN, Sugar EA, Onners B, Solt S, Zheng L, Diaz LA, Jr., Donehower RC, Jaffee EM and Laheru DA. Evaluation of ipilimumab in combination with allogeneic pancreatic tumor cells transfected with a GM-CSF gene in previously treated pancreatic cancer. J Immunother. 2013; 36:382-389.

18. Lutz ER, Wu AA, Bigelow E, Sharma R, Mo G, Soares K, Solt S, Dorman A, Wamwea A, Yager A, Laheru D, Wolfgang CL, Wang J, Hruban RH, Anders RA, Jaffee EM, et al. Immunotherapy converts nonimmunogenic pancreatic tumors into immunogenic foci of immune regulation. Cancer Immunol Res. 2014; 2:616-631.

19. Feig C, Jones JO, Kraman M, Wells RJ, Deonarine A, Chan DS, Connell CM, Roberts EW, Zhao Q, Caballero
OL, Teichmann SA, Janowitz T, Jodrell DI, Tuveson DA and Fearon DT. Targeting CXCL12 from FAP-expressing carcinoma-associated fibroblasts synergizes with antiPD-L1 immunotherapy in pancreatic cancer. Proc Natl Acad Sci U S A. 2013; 110:20212-20217.

20. Zhu Y, Knolhoff BL, Meyer MA, Nywening TM, West BL, Luo J, Wang-Gillam A, Goedegebuure SP, Linehan DC and DeNardo DG. CSF1/CSF1R blockade reprograms tumorinfiltrating macrophages and improves response to T-cell checkpoint immunotherapy in pancreatic cancer models. Cancer Res. 2014; 74:5057-5069.

21. Beatty GL, Torigian DA, Chiorean EG, Saboury B, Brothers A, Alavi A, Troxel AB, Sun W, Teitelbaum UR, Vonderheide RH and O'Dwyer PJ. A phase I study of an agonist CD40 monoclonal antibody (CP-870,893) in combination with gemcitabine in patients with advanced pancreatic ductal adenocarcinoma. Clin Cancer Res. 2013; 19:6286-6295.

22. Elgueta R, Benson MJ, de Vries VC, Wasiuk A, Guo Y and Noelle RJ. Molecular mechanism and function of CD40/ CD40L engagement in the immune system. Immunol Rev. 2009; 229:152-172.

23. Vonderheide RH, Bajor DL, Winograd R, Evans RA, Bayne LJ and Beatty GL. CD40 immunotherapy for pancreatic cancer. Cancer Immunol Immunother. 2013; 62:949-954.

24. Luheshi N, Davies G, Poon E, Wiggins K, McCourt M and Legg J. Th1 cytokines are more effective than Th2 cytokines at licensing anti-tumour functions in CD40activated human macrophages in vitro. Eur J Immunol. 2014; 44:162-172.

25. Beatty GL, Chiorean EG, Fishman MP, Saboury B, Teitelbaum UR, Sun W, Huhn RD, Song W, Li D, Sharp LL, Torigian DA, O'Dwyer PJ and Vonderheide RH. CD40 agonists alter tumor stroma and show efficacy against pancreatic carcinoma in mice and humans. Science. 2011; 331:1612-1616.

26. Beatty GL, Winograd R, Evans RA, Long KB, Luque SL, Lee JW, Clendenin C, Gladney WL, Knoblock DM, Guirnalda PD and Vonderheide RH. Exclusion of $\mathrm{T}$ Cells From Pancreatic Carcinomas in Mice Is Regulated by Ly6C(low) F4/80(+) Extratumoral Macrophages. Gastroenterology. 2015; 149:201-210.

27. Winograd R, Byrne KT, Evans RA, Odorizzi PM, Meyer AR, Bajor DL, Clendenin C, Stanger BZ, Furth EE, Wherry EJ and Vonderheide RH. Induction of T-cell Immunity Overcomes Complete Resistance to PD-1 and CTLA-4 Blockade and Improves Survival in Pancreatic Carcinoma. Cancer Immunol Res. 2015; 3:399-411.

28. Nomi T, Sho M, Akahori T, Hamada K, Kubo A, Kanehiro H, Nakamura S, Enomoto K, Yagita H, Azuma M and Nakajima Y. Clinical significance and therapeutic potential of the programmed death-1 ligand/programmed death-1 pathway in human pancreatic cancer. Clin Cancer Res. 2007; 13:2151-2157.

29. Sandin LC, Eriksson F, Ellmark P, Loskog AS, Totterman TH and Mangsbo SM. Local CTLA4 blockade effectively 
restrains experimental pancreatic adenocarcinoma growth in vivo. Oncoimmunology. 2014; 3:e27614.

30. Vignali DA and Kuchroo VK. IL-12 family cytokines: immunological playmakers. Nat Immunol. 2012; 13:722-728.

31. Becher B, Schlitzer A, Chen J, Mair F, Sumatoh HR, Teng KW, Low D, Ruedl C, Riccardi-Castagnoli P, Poidinger M, Greter M, Ginhoux F and Newell EW. High-dimensional analysis of the murine myeloid cell system. Nat Immunol. 2015; 15:1181-1189.

32. Damuzzo V, Pinton L, Desantis G, Solito S, Marigo I, Bronte V and Mandruzzato S. Complexity and challenges in defining myeloid-derived suppressor cells. Cytometry B Clin Cytom. 2015; 88:77-91.

33. Taylor PR, Brown GD, Geldhof AB, MartinezPomares L and Gordon S. Pattern recognition receptors and differentiation antigens define murine myeloid cell heterogeneity ex vivo. Eur J Immunol. 2003; 33:2090-2097.

34. Zippelius A, Schreiner J, Herzig P and Muller P. Induced PD-L1 expression mediates acquired resistance to agonistic anti-CD40 treatment. Cancer Immunol Res. 2015; 3:236-244.

35. Vonderheide RH and Glennie MJ. Agonistic CD40 antibodies and cancer therapy. Clin Cancer Res. 2013; 19:1035-1043.

36. Marzec M, Zhang Q, Goradia A, Raghunath PN, Liu X, Paessler M, Wang HY, Wysocka M, Cheng M, Ruggeri BA and Wasik MA. Oncogenic kinase NPM/ALK induces through STAT3 expression of immunosuppressive protein CD274 (PD-L1, B7-H1). Proc Natl Acad Sci U S A. 2008; 105:20852-20857.

37. Parsa AT, Waldron JS, Panner A, Crane CA, Parney IF, Barry JJ, Cachola KE, Murray JC, Tihan T, Jensen MC, Mischel PS, Stokoe D and Pieper RO. Loss of tumor suppressor PTEN function increases B7-H1 expression and immunoresistance in glioma. Nat Med. 2007; 13:84-88.

38. Noman MZ, Desantis G, Janji B, Hasmim M, Karray S, Dessen P, Bronte V and Chouaib S. PD-L1 is a novel direct target of HIF-1alpha, and its blockade under hypoxia enhanced MDSC-mediated T cell activation. J Exp Med. 2014; 211:781-790.

39. Conroy T, Desseigne F, Ychou M, Bouche O, Guimbaud R, Becouarn Y, Adenis A, Raoul JL, Gourgou-Bourgade $\mathrm{S}$, de la Fouchardiere C, Bennouna J, Bachet JB,
Khemissa-Akouz F, Pere-Verge D, Delbaldo C, Assenat E, et al. FOLFIRINOX versus gemcitabine for metastatic pancreatic cancer. N Engl J Med. 2011; 364:1817-1825.

40. Von Hoff DD, Ervin T, Arena FP, Chiorean EG, Infante J, Moore M, Seay T, Tjulandin SA, Ma WW, Saleh MN, Harris M, Reni M, Dowden S, Laheru D, Bahary N, Ramanathan RK, et al. Increased survival in pancreatic cancer with nab-paclitaxel plus gemcitabine. N Engl J Med. 2013; 369:1691-1703.

41. Suzuki E, Kapoor V, Jassar AS, Kaiser LR and Albelda SM. Gemcitabine selectively eliminates splenic Gr-1+/ $\mathrm{CD} 11 \mathrm{~b}+$ myeloid suppressor cells in tumor-bearing animals and enhances antitumor immune activity. Clin Cancer Res. 2005; 11:6713-6721.

42. Kroemer G, Galluzzi L, Kepp O and Zitvogel L. Immunogenic cell death in cancer therapy. Annu Rev Immunol. 2013; 31:51-72.

43. Homma Y, Taniguchi K, Nakazawa M, Matsuyama R, Mori R, Takeda K, Ichikawa Y, Tanaka K and Endo I. Changes in the immune cell population and cell proliferation in peripheral blood after gemcitabine-based chemotherapy for pancreatic cancer. Clin Transl Oncol. 2013; 16:330-335.

44. Nowak AK, Robinson BW and Lake RA. Synergy between chemotherapy and immunotherapy in the treatment of established murine solid tumors. Cancer Res. 2003; 63:4490-4496.

45. Corbett TH, Roberts BJ, Leopold WR, Peckham JC, Wilkoff LJ, Griswold DP, Jr. and Schabel FM, Jr. Induction and chemotherapeutic response of two transplantable ductal adenocarcinomas of the pancreas in $\mathrm{C} 57 \mathrm{BL} / 6$ mice. Cancer Res. 1984; 44:717-726.

46. Wang Y, Zhang Y, Yang J, Ni X, Liu S, Li Z, Hodges SE, Fisher WE, Brunicardi FC, Gibbs RA, Gingras MC and Li $\mathrm{M}$. Genomic sequencing of key genes in mouse pancreatic cancer cells. Curr Mol Med. 2012; 12:331-341.

47. Bruns CJ, Harbison MT, Kuniyasu H, Eue I and Fidler IJ. In vivo selection and characterization of metastatic variants from human pancreatic adenocarcinoma by using orthotopic implantation in nude mice. Neoplasia. 1999; 1:50-62.

48. Elso CM, Roberts LJ, Smyth GK, Thomson RJ, Baldwin TM, Foote SJ and Handman E. Leishmaniasis host response loci (lmr1-3) modify disease severity through a Th1/Th2independent pathway. Genes Immun. 2004; 5:93-100. 